\title{
Correio Aéreo e aviação civil: Os primeiros passos da Varig
}

\author{
Air mail and civil aviation: The first steps of Varig
}

Susana de Araújo Gastal (GASTAL, S. A.) ${ }^{*}$

\begin{abstract}
RESUMO - O Turismo está entre as marcas do século XX, quando a organização das viagens e a sua formatação como produto para comercialização no mercado de lazer se dá plenamente, no denominado turismo de massa. Apesar de sua forte presença por mais de um século, haveria certa tendência a estudar o Turismo em separado, isolando-o da sua interdependência com os momentos históricos e situações sócio-culturais onde ele é gerado. Isto leva, entre outros, a que a contribuição que os Correios deram às viagens, inclusive na introdução do transporte aéreo no Brasil, seja relevada. O presente artigo analisa essa inter-relação, em especial associada à criação da empresa aérea Viação Aérea Rio-Grandense - Varig, buscando desenhar o campo de forças que levou à formação do sistema aéreo brasileiro, para além dos discursos laudatórios que destacam participações individuais no processo.
\end{abstract}

Palavras-chave: Turismo; Aviação Brasileira; Correio Aéreo; Varig.

ABSTRACT - Tourism was an important activity of the twentieth century. This was so due to the organization of traveling as a product in the marketing place such as the mass tourism. Despite its strong presence for more than a century, there would be some tendency to study Tourism as something apart from its interdependent situation with the historical and socio-cultural moments. In these terms, the contribution of the Air Mail Service is very important. The Brazilian Air Transportation depended on Air Mail Transportation to survive in its early days. This article examines this question, particularly associated with the creation of Viação Aérea Rio-Grandense - Varig, aiming to outline the field of forces that led to the formation of the Brazilian air system, as well as to look at the laudatory speeches about individual holdings in the process.

Key words: Tourism; Brazilian Air Transportation; Air Mail Service; Varig.

\footnotetext{
* Graduação em Comunicação Social pela Pontifícia Universidade Católica do Rio Grande do Sul (PUCRS). Mestrado em Artes Visuais pela Universidade Federal do Rio Grande do Sul (UFRGS). Doutorado em Comunicação Social (PUCRS). Professora e pesquisadora do Mestrado em Turismo da Universidade de Caxias do Sul (UCS) e dos cursos de graduação em Turismo da UCS e da PUCRS. Endereço: Rua Francisco Getulio Vargas (Petrópolis). CEP: 95070-560 - Caxias do Sul, RS (Brasil). Telefone: (54) 3218-2100 Ramal: 2621. Fax: (54) 3218-2143. Email: susanagastal@ gmail.com
} 


\section{INTRODUÇÃO ${ }^{1}$}

O Turismo está entre os fenômenos alavancados pela Revolução Industrial, no que significou em avanços das comunicações e dos transportes; esses permitiram a organização das viagens e a sua formatação como produto para comercialização no mercado de lazer. Pela abrangência que as viagens ganham, Boyer (2003) usa a expressão revolução turística para qualificar suas implicações, colocando o Turismo, inclusive, entre as grandes revoluções inglesas do século XVIII, entre elas a própria revolução industrial. Apesar desta abrangência, haveria certa tendência a estudar o Turismo em separado, isolando-o da sua interdependência com os momentos históricos e situações sócio-culturais onde ele é gerado. Isto leva, entre outros, a que a contribuição que os Correios deram às viagens, inclusive na introdução do transporte aéreo no Brasil, seja ignorada.

Esta interdependência pode ser vista já no século XVIII, início da revolução turística, quando um ativo mercado editorial ditava conselhos sobre o como viajar, publicando "uma onda de crônica de viagens e [...] manuais que, mediante contínua atualização, alcançavam ampla difusão". (SCHMIDT, 1987, p. 17). Goethe esteve entre os viajantes que publicaram relatos sobre suas muitas viagens, recebendo, inclusive, adiantamentos em dinheiro dos editores, para subsidiar os seus deslocamentos. Schmidt (1987), ao analisar as viagens de Goethe, explica que boa parte delas era feita "no interior de diligências que andavam aos solavancos" (p. 20). Mas, mais importantes, estas eram diligências postais, ou seja, aquelas encarregadas de transportar correspondência. Isso lhes permitia colocar à disposição dos viajantes, "tabelas de distâncias e mapas sinópticos sobre a rede de estradas cobertas pelas diligências". (p. 20). Ele ainda acrescenta: “As reservas de refeições e pernoites eram feitos por ocasião das inscrições dos viajantes na lista de passageiros, e notificada com antecedência aos chefes das estações por meio de volantes" (p. 20). As paradas eram em "estações postais, que ofereciam a alimentação e as estalagens". (p. 20). Já no início do século XX, a presença dos Correios estará associada à criação de empresas aéreas e à

\footnotetext{
${ }^{1}$ As informações contidas neste artigo são parte dos resultados do projeto de pesquisa "O Campo Turístico e suas Construções no Rio Grande do Sul. 1935-2000", realizada com apoio do Conselho Nacional de Desenvolvimento Científico e Tecnológico (CNPq) e da Universidade de Caxias do Sul.
} 
implantação de suas rotas. A história da empresa aérea brasileira Viação Aérea RioGrandense - Varig, não fugiu a essa regra.

O percurso da Varig acompanhou, em muitos momentos, a construção do Turismo no Brasil, não só por sua atividade precípua, ou seja, o transporte aéreo, mas porque em alguns momentos a empresa investiu, inclusive, em hotéis e, mais importante, por muitas décadas suas agências no exterior transformaram-se em grandes representantes do país, pois atendiam cidadãos brasileiros no exterior, ajudando-os a resolver problemas que seriam de competência dos consulados locais, do país. Resgatar a história da Varig, entretanto, não se mostrou uma tarefa fácil, em que pese à grande quantidade de material presente em livros, artigos e, em especial, em sites da Internet. Este material é, em sua maioria, construído para alimentar um imaginário de pioneirismo e apresentar a figura de Otto Meyer, o fundador, como self made man. Estas narrativas tendem a desconhecer o fato de que, naquele momento - a década de 1920 -, o Brasil despertava a sua mentalidade aeronáutica, e que no país e na América do Sul, diferentes empresas e rotas foram implantadas.

Sem cair nos extremos de alguns, que vêem na criação da Varig e de outras empresas latino-americanas, nas décadas iniciais do século XX, em que houve importante presença de alemães e de germano-descendentes, como a constituição de um braço do nascente movimento nazista alemão, o presente resgate analisa e procura avaliar como teria se constituído no país esta intricada teia do transporte aéreo. Para tal, é necessário reportar a um momento anterior e a um cenário mais amplo, a América do Sul, a partir da criação da Sociedad Colombo-Alemana de Transportes Aereos - Scadta, na Colômbia; e no Brasil, considerar várias iniciativas oficiais que levaram à criação da Aeronáutica como uma das Forças Armadas, e as normativas que incentivavam a instalação de rotas aéreas por grupos privados. Nos dois casos, a atividade de Correio Aéreo teve uma importância e um papel que não pode ser desconsiderado.

Os dados aqui apresentados são resultados de uma pesquisa mais ampla, que objetiva traçar a construção do campo do Turismo no Rio Grande do Sul, ao longo do século XX. A construção teórico-metodológica proposta para o resgate dessas construções de sentido, procura aproximar as noções de sistema simbólico, campo e habitus, em Pierre Bourdieu (1983); a teoria do texto, conforme Roland Barthes (1988) e a teorização de Fredric Jameson (1992), no que esta avança para problematizar 
dialeticamente o princípio marxista da infraestrutura e da superestrutura, frente à pósmodernidade. A amarrar as três vertentes, uma aproximação de caráter semiótico, presente em todas elas, pois se centram na questão do resgate dos percursos de construção de sentido. Por campo entenda-se o "espaço onde se manifestam relações de poder, o que implica afirmar que ele se estrutura a partir da distribuição desigual de um quantum social, o quantum entendido como capital social" (ORTIZ in: BOURDIEU, 1983, p. 21).

Para o segmento da pesquisa aqui apresentado, realizou-se uma revisão bibliográfica incluindo livros, artigos e muito especialmente, teses e dissertações que abordam o percurso da Varig, além de textos-depoimento, como o de LavenereWanderley (1975), cuja carreira militar na Aeronáutica esteve muito associada aos primórdios da Força Aérea Brasileira e à implantação do Correio Aéreo Nacional. Outros textos, cuja contribuição à pesquisa foi fundamental, versam sobre a história do Correio Aéreo, como o de William Victor Kriebel (1996), além de documentos produzidos por entidades filatélicas.

\title{
2 PRIMÓRDIOS DA AVIAÇÃO NA AMÉRICA DO SUL
}

As décadas de 1920 e 1930 vêem criar, no Brasil, a "mentalidade aeronáutica" (SOUZA, 1986, p. 32). Lavenere-Wanderley ${ }^{2}$, por sua vez, cita Eduardo Gomes para colocar o processo sob o ponto de vista militar, e apresenta sua data inicial ainda no século XIX:

\begin{abstract}
A 24 de junho de 1867 [...] subia aos ares, no Teatro de Operações da Guerra da Tríplice Aliança, um balão de observação - o primeiro emprego militar aeronáutico na América do Sul e a semente daquilo que, muito mais tarde, veio a transformar-se na Força Aérea Brasileira. A Aeronáutica teve em nossas terras, destinação militar, pois militar nasceu e se desenvolveu entre militares (Eduardo Gomes in: LAVENERE-WANDERLEY, 1975, p. 9).
\end{abstract}

Em 13 de janeiro de 1913 é criada a Escola Brasileira de Aviação, para capacitar os pilotos de que o país necessitava, "semelhante às melhores da Europa e com uma

\footnotetext{
${ }^{2}$ Nelson Freire LAVENERE-WANDERLEY foi um dos pilotos do primeiro vôo do Serviço Postal Aéreo Militar - SPAM, realizado em 12 de junho de 1931, entre Rio de Janeiro e São Paulo. O SPAM logo passaria a ser denominado como Correio Aéreo Militar - CAM.
} 
flotilha de aviões Bleriot e Farman, monoplanos e biplanos, com motores de várias potências, adequados para instrução, para realização de provas para os brevets e para o vôo com passageiros" (LAVENERE-WANDERLEY, 1975, p. 33). A iniciativa é fruto de um acordo firmado entre o ministro da Guerra, general Vespasiano Albuquerque, e um grupo de pilotos italianos (KRIEBEL, 1996). O início da Escola se dá, de fato, em fevereiro de 1914, com a chegada ao Campo dos Afonsos, onde hangares e oficinas são construídos, dos primeiros aviões e dos 35 militares que comporiam a turma inicial. Mas, já em junho, a Escola rescinde contrato com o governo, pois há atrasos nos pagamentos e dificuldade na importação de peças e equipamentos, devido à eclosão da guerra na Europa. A Escola é fechada. A Marinha retomará a formação de pilotos em 1916; o Exército apenas em 1919. (LAVENERE-WANDERLEY, 1975).

Os problemas com a importação de peças e equipamentos levam o capitão do Exército Marcos Evangelista da Costa Vilela Junior a construir dois aviões, o $\mathrm{Aribu}^{3} \mathrm{em}$ 1917, e o Alagoas em 1918, que realizam vários vôos.

O seu avião 'Alagoas' tinha a célula toda de madeira nacional e nela empregara a gameleira, a itapecerica, o jenipapo e a ingarana. Chegou mesmo a fazer o trem de aterragem de jenipapo. Foram também construídas por ele as hélices, sendo de sua composição até o verniz. Quando todo mundo pensava no emprego do tecido de linho ou de seda, para tela de avião, Villela Junior teve oportunidade de dizer, após demorados estudos, que o tecido de algodão dará melhores resultados; na fábrica de tecidos em Deodoro, obtida permissão para ali fazer suas experiências, obteve tão boa tela que a fábrica mandou colocá-la na Exposição de Buenos Aires, em 1918, onde foi premiada com medalha de ouro [...]. ${ }^{4}$ (LAVENERE-WANDERLEY, 1975, p. 44)

Ainda segundo Lavenere-Wanderley (1975, p. 44):

Minhas hélices eram feitas no galpão, nos fundos de minha própria casa no Realengo, onde cheguei a construir mais de 25. Com orgulho digo: fiz um desenho 'sui-generis', estabeleci os quatorze coeficientes, trabalhei largo tempo e construí uma balança para o equilíbrio das hélices. Enquanto outros procuravam fazer hélices de peroba, de açoita-cavalo e de nogueira, ensaiando mais de oito carregamentos de carroças de diferentes madeiras, cheguei a conclusão que a ingarana era superior a todas as madeiras indicadas.

\footnotetext{
${ }^{3} \mathrm{O}$ nome reportaria aos sonhos que o construtor teria quando criança, quando voava como um urubu.

${ }^{4} \mathrm{Na}$ verdade, em dezembro de 1915 já entravam em vôo os Junkers-J, primeira aeronave toda em metal, feita em Duralumin, uma versão prévia do alumínio. (KRIEBEL, 1996).
} 
No mesmo ano de 1917, teriam sido realizados no país "337 vôos; o vôo mais alto foi feito pelo Tenente Schorcht, atingindo 1.500 metros de altitude e vôo de maior duração, com 3 horas, foi feito pelo Tenente De Lamare" (LAVENEREWANDERLEY, 1975, p. 56). Mesmos que as autoridades estivessem conscientes das vantagens das viagens aéreas, as ações práticas demoravam a se desenvolver.

Mas, os problemas não estariam apenas no Brasil. A guerra dera um grande impulso à aviação e, findo o conflito, havia excesso de aviões militares ${ }^{5}$ e de pessoal treinado, além de fábricas ociosas, tanto nos Estados Unidos como na Europa. Se, no período, não havia maior interesse pela América do Sul por parte dos Estados Unidos, o mesmo não acontecia com a Alemanha. O Tratado de Versalhes a proibira de desenvolver qualquer forma de aviação militar, bem como de subscrever o International Convention on Air Navegation, que autorizava o livre trânsito internacional no espaço aéreo e discriminava empresas não subscritas. (KRIEBEL, 1996). A Alemanha, então, forma companhias "nacionais" nos Bálcãs, para obter os landing rights em países onde, de outra forma, estes direitos de aterragem lhe seriam negados. "A América do Sul, relativamente livre da dominação francesa e inglesa, e já possuindo uma grande população germânica, criando-lhe uma atmosfera favorável, estava madura para o desenvolvimento 'nacional' local de facilidades de transporte aéreo." (KRIEBEL, 1996, p. 7). Acrescente-se ainda que, nas primeiras décadas do século $X X$,

[...] vias terrestres eram precariamente desenvolvidas em muitas partes da América Latina, resultado de condições geográficas e econômicas. Em muitos lugares, aviões foram descobertos não só como transporte eficiente e mais seguro e, não raro, os únicos meios de transporte. Os governos latinoamericanos foram, portanto, favoráveis a concessão de franquias para os empreendedores que desejassem - e que fossem financeiramente capazes de investir - desenvolver serviços aéreos em suas respectivas regiões. (KRIEBEL, 1996, p. 89).

Na América do Sul não havia uma indústria aeronáutica implantada, nem capitais disponíveis para investimento no setor. Casos como o do Aribu e do Alagoas são experiências isoladas, que só ratificam a precariedade industrial do país e da região. Desta forma, o projeto alemão na América do Sul "parece seguir um desenho cuidadoso" (idem, p. 7), em especial nos casos de sua presença na Colômbia, Peru e

\footnotetext{
${ }^{5}$ A Alemanha construíra 24 aviões em 1911, em 1917 seriam 19.746 e, em 1918, até o final da guerra, já construíra 14.123 aeronaves. (KRIEBEL, 1996).
} 
Brasil. As companhias incorporadas nacionalmente recebiam salvaguardas dos governos locais, além de serem tratadas com maior liberalidade nas concessões, do que as companhias estrangeiras ${ }^{6}$. Neste contexto, surge na Colômbia a Sociedad ColomboAlemana de Transportes Aereos - SCADTA, em 1919, e "mesmo que fundos governamentais alemães não estivessem diretamente envolvidos, a SCADTA recebeu ajuda da indústria aérea germânica”. (KRIEBEL, 1996, p. 7). Em 1925 é a vez da Bolívia, com a criação da Lloyd Aéreo Boliviano - LAB, com apoio da empresa aérea German Junker. E, em 1926, será criada a Varig. (idem)

A SCADTA fora fundada por cinco negociantes colombianos, sendo três deles germano residentes, a partir de uma iniciativa do austríaco Peter Paul von Bauer. Suas primeiras aeronaves serão dois hidroaviões Junkers F13 que, quando entregues, vieram conduzidos por pilotos alemães que, depois, ficaram atuando no local, inaugurando uma prática que passaria a ser a usual. (KRIEBEL, 1996, p. 120). A empresa começa a voar em 1920, unindo Bogotá ao porto de Barraquilla, uma distância de 650 milhas, que os aviões percorriam em sete horas. O mesmo percurso entre os dois destinos, até então realizado apenas por um combinado trem-barco (não raro, também mulas e cavalos) demorava uma semana no período das chuvas, mas poderia chegar a um mês no período das secas. Barraquilla era estratégica tanto para alcançar o interior do país, através do rio Madalena, como para "facilitar a ligação entre o Pacífico e os portos do Caribe, o que convenceu o governo colombiano a dar suporte a qualquer tentativa de vencer a distância por ar.” (KRIEBEL, 1996, p. 119).

Para voar na Colômbia e alcançar sua capital Bogotá, entretanto, os aviões precisaram de várias adaptações, entre elas a de um radiador para resfriamento e uso de rodas de automóvel, pois, a "América do Sul, como foi logo aprendido, não era a Europa”. (KRIEBEL, 1996, p. 120). Ainda segundo Kriebel (1996) ${ }^{7}$, estas e outras dificuldades tornaram mais morosa a expansão e mesmo a continuidade dos serviços, o que levou a entrada de Peter Paul von Bauer no negócio, na virada de 1920 para 1921. Ele vivera na América do Sul entre 1908 e 1916, retornando a Colômbia em 1920, como representante da fabricante alemã de aviões Junker. Em 1922, tornou-se diretor da SCADTA. Geógrafo de formação, criou na empresa uma divisão científica para realizar

\footnotetext{
${ }^{6} \mathrm{O}$ Brasil, especificamente, ainda não assinara convenções internacionais do ar, mas a atuação em território nacional dependia de autorização das autoridades locais.

${ }^{7}$ Todas as informações deste parágrafo serão de Kriebel (1996).
} 
pesquisa aérea e mapeamentos para o governo; também estabeleceu ligações com várias capitais européias e outras grandes cidades, incluindo Nova York, onde instalou agências com farto material promocional e "selos especiais (impressos com temas colombianos), nelas e na maioria dos consulados colombianos, de maneira que o mundo logo soubesse que a SCADTA havia chegado e era 'a`empresa aérea na América do Sul.” (KRIEBEL, 1996, p. 120).

Este aprofundamento da experiência colombiana é importante para o entendimento do futuro processo do transporte aéreo no Brasil, inclusive no Rio Grande do Sul, por duas razões: a presença da função de Correio Aéreo, desenvolvido pela SCADTA, e a criação da Condor Syndikat, como será apresentado a seguir.

O Correio Aéreo foi fundamental para o desenvolvimento da aviação na América do Sul. A carência de capitais financeiros, unida a precariedade de comunicações, era desafio para as autoridades de todas as localidades. Por outro lado, a irregularidade dos vôos e a periculosidade que ainda os acompanhava, tornava a situação mais dramática, pois constrangia a sua utilização para o transporte de passageiros. "O Correio foi, então, a resposta para desenvolver e sobreviver" (KRIEBEL, 1996, p. 7), com contratos de transporte subsidiados, que permitissem criar linhas de comunicação. Ao mesmo tempo, para os governos locais os contratos de Correio Aéreo eram a alternativa menos onerosa para os serviços de que necessitavam. O subsídio era dado na forma de outorga dos serviços e conseqüente autorização para comercialização de selos. No caso da SCADTA,

[...] o governo autorizou a questão dos selos para estes serviços, como uma forma de subsídio, mesmo que indireta. Entretanto, note-se que o governo autorizou a arrecadação de fundos via selos, mas não deliberou sobre a maneira de fazê-lo ou impôs como exigências que os temas dos selos tivessem [a prévia] aprovação governamental. Mais tarde, não foi este o caso do Brasil, onde o governo exigiu das linhas domésticas - ETA, Varig e Condor - que, em matéria de selos para seus fundos, os designs contassem com aprovação oficial”. (KRIEBEL, 1996, p.120).

O crescimento da SCADTA, cujas linhas alcançavam inclusive os Estados Unidos em 1924, levou Von Bauer a pensar numa Scadta Internacional. Precisando de mais aviões e de financiamentos, retornou a Alemanha, quando nasce a nova empresa, a Condor Syndikat, uma associação entre a Deutscher Aero Lloyd A. G., predecessora da 
Luft Hansa ${ }^{8}$, com a Schlubach, Theimer and Co, de Hamburgo e a própria SDACTA (KRIEBEL, 1996). Ainda segundo Kriebel, "não é claro o porquê do nome Condor, um abutre andino, ter sido escolhido. Ele não é nativo da Alemanha.” (1996, p. 120). A Condor Syndikat não seria propriamente uma empresa aérea, embora por um curto período tenha atuado como tal no Brasil, mas talvez estivesse mais aproximada do que hoje são as empresas de logística:

Os objetivos da nova empresa eram os de estudar a viabilidade de operações aéreas na América do Sul, incluindo a possibilidade de vôos transatlânticos, além de promover o Junker e outras aeronaves alemãs, agora exportadas para compensar os efeitos devastadores da guerra. Fritz Hammer, que se tornaria a figura catalisadora para o desenvolvimento de muitas linhas aéreas na América do Sul, foi nomeado diretor de marketing da Syndikat. (KRIEBEL, 1996, p. 121).

A figura de Hammer passará a ser uma presença constante. Quem era ele?

Fritz Wilhelm Hammer nasceu em 6 de dezembro de 1888, em Berlin. Após estudar na Technischen Hochschule em Munique e Berlin (equivalente ao Massachusetts Institute of Technology) e na [...] Machine Building School em Hildburghausen, ele foi para a escola de vôo e se tornou piloto em 1913, o mesmo ano em que recebeu um prêmio nacional por um vôo de oito horas. Durante a guerra, Hammer trabalhou no treinamento de pilotos e observadores, e participou no desenvolvimento de uma base para aviões torpedo. Mais tarde foi transferido para o front e, em 1915, teve a seu encargo quatro seaplanes, ou melhor, float-planes - aviões terrestres equipados com pontões (pontoons) em vez de rodas ou sapatas. (KRIEBEL, 1996, 121-122).

Ele chega à Colômbia com os primeiros aviões da SCADTA. O crescimento dessa empresa, logo exige aviões mais sofisticados e com maior autonomia de vôo do que os Junker, levando a SCADTA e a Condor Syndikat a investir no Domier Wals, um avião fabricado por grupos alemães na Itália:

O Wal (de whale, baleia), com vôo em novembro de 1922 [...] era capaz de transportar dez passageiros; a cabine para dois tripulantes posiciona-se abaixo das asas [...]. O corpo era de metal Duralumin, o mesmo material utilizado no F13 e, depois, nos Zeppelins. [...] Vários modelos e máquinas foram produzidos durante o ciclo Wal. Num acerto com a Syndikat, Hammer retorna a Colômbia com dois Wals em criação e com outro piloto, seu velho amigo e antigo piloto de guerra, Freiherr Von Buddenbrock. [...] Em cerca de 10 de agosto de 1925, esses Wals, denominados Atlântico e Pacífico, com as

\footnotetext{
${ }^{8}$ Deutsche Luft Hansa Aktiengesellschaft, ou simplesmente Luft Hansa, só passará a Lufthansa em 1933.
} 
cores da Colômbia, realizam um vôo comercial no sentido anti-horário, no Caribe, parando em todos os países da América Central e finalmente chegando a Havana, Cuba, em 19 de setembro. (KRIEBEL, 1996, p. 123-4).

Como se verá adiante, o Atlântico será um equipamento fundamental na constituição da Varig. Antes, porém, como parte de seu avanço empresarial pelo Caribe, Hammer fez uma tentativa de entrar no mercado americano, com o mesmo Atlântico. Hammer realizou uma viagem experimental, em 1925, entre a Colômbia e Palm Beach, na Flórida, "utilizando dois hidroaviões Dornier Wal, um dos quais tinha a matrícula D1012 e era batizado Atlântico. Além de analisar a viabilidade da rota, a viagem serviu como tour promocional da indústria aeronáutica alemã no Continente" ${ }^{\text {, }}$, mas também para viabilizar os planos de expansão da SCADTA. "A cada parada, avião e homens eram admirados e Von Bauer garantia passageiros e compromissos de Correio dos governos locais”. (KRIEBEL, 1996, p. 123).

A tentativa de entrar nos Estados Unidos com vôos comerciais e Correio Aéreo, entretanto, seria abortada, pois as autoridades americanas desconfiavam da presença germânica na empresa e preferiram que as rotas comerciais e o Correio Aéreo no país fossem explorados pela PAN AM, empresa que ainda seria criada nos anos seguintes, por incentivo governamental, justamente com a finalidade de contrapor à presença alemã. Outro fato importante, em 1926, a união da Junkers Luftverkehr e da Deutscher Aero Lloyd leva a formação da Deutsch Luft Hansa" ${ }^{10}$. A Condor Syndikat aparentemente mantém sua identidade e missão. O interesse na operação de vôos na América do Sul se intensifica, mas agora na costa leste.” (KRIEBEL, 1996, p. 124).

Daí, também, os desdobramentos para o Brasil, levando a que LavenereWanderley (1975, p. 59) pudesse afirmar que, terminada a Guerra, a aviação nacional “entra, então, numa fase de consolidação e expansão". Este será também o período em que

[...] Otto Ernest Meyer estava em processo de formar uma empresa aérea local [...], no Rio Grande do Sul. Procurando obter o melhor equipamento e equipe, ele foi à Alemanha e contatou com a Condor Syndikat, no início de novembro de 1926. Nesta função, e oferecendo compartilhar $21 \%$ do capital de sua futura empresa, ele teve a oferta do Wal Atlântico e de suporte técnico, mas só receberia o avião e a autorização para operar sua linha, sete meses mais tarde. (KRIEBEl, 1996, p. 125).

\footnotetext{
${ }^{9}$ Disponível em: <http://edairways.sites.uol.com.br/varig.htm>. Acesso em: janeiro de 2009.

${ }^{10}$ Ver nota 8.
} 
Na década de 1920, no Brasil, a aviação ainda era marcada por iniciativas individuais, mesmo que ousadas. Por seu posicionamento estratégico entre grandes centros do cone sul - Buenos Aires/Montevidéu e Rio de Janeiro/São Paulo - várias cidades do Rio Grande do Sul eram envolvidas nas escalas desses vôos pioneiros. Por exemplo, em 1920 há o reide Rio-Buenos Aires, buscando incrementar a ligação entre as duas cidades, e que teve saídas simultâneas de cada uma delas. Os brasileiros voam num hidroavião de construção italiana; decolam do Rio de Janeiro, fazem escala em Santos, mas, na altura de Balneário Camboriú há uma avaria que os obriga a descer e, na aterragem, batem numa pedra submersa. Reparados os danos, a viagem prossegue, não sem outros contratempos. Entre suas escalas, no Rio Grande do Sul aterriza na praia de Cidreira, na lagoa dos Patos, no Guaíba e nas cidades de Pelotas e Rio Grande onde, "a tentativa de reide foi, lamentavelmente, interrompida, por ter o hidroavião caído do guindaste que o içava para colocá-lo a seco no cais, a fim de sofrer revisão". (LAVENERE-WANDERLEY, 1975, p. 61). Apenas meses depois, outro vôo conseguirá realizar o percurso, levando quatro dias para percorrer a distância entre Rio de Janeiro e Buenos Aires.

A aviação militar também chega ao Rio Grande do Sul em 1921, quando o capitão Graciliano de Negreiros é designado para obter, na cidade de Santa Maria, o terreno necessário ao campo de aviação. (LAVENERE-WANDERLEY, 1975) Os equipamentos para o mesmo são transportados por trem e por barco, este trazendo material vindo diretamente da França. Outro campo de aviação é preparado em Alegrete. No ano seguinte, em 5 de junho, o ministro da Guerra "criou, na $3^{\text {a }}$ Região Militar, um Grupo de Esquadrilhas de Aviação, subordinado diretamente ao Comandante da Região, quanto à disciplina, administração e instrução tática, e ao Estado-Maior do Exército, quanto à instrução técnica e inspeção geral” (idem, p. 80), sendo composto por uma Esquadrilha de Bombardeio com quatro aviões, uma Esquadrilha de Caça, com nove aviões, e a Esquadrilha de Observação, com seis aviões, esta última sediada em Alegrete. Em 1928 o grupo de esquadrilhas é dissolvido e, em 1930, o material de aviação das duas cidades é encaminhado para o Campo dos Afonsos, no Rio de Janeiro (idem). 


\section{VARIG: PRIMEIROS PASSOS}

A história da Varig, no seu início, está associada à Condor Syndikat, criada em 1924, na Alemanha, pelo engenheiro e piloto Fritz Hammer e por Peter von Bauer, reunindo as empresas Aero Lloyd, Schlubach Teimer e Scadta, primeiramente para viabilizar a ligação aérea entre Estados Unidos e Colômbia, via América Central. Na mesma época, Otto Ernst Meyer, que fora oficial aviador da Força Aérea alemã, iniciaria as tratativas para criar uma empresa aérea no Brasil. (KRIEBEL, 1996).

Meyer nascera na província prussiana de Hanover, em 25 de novembro de 1875 (idem); alemão de nascimento, depois naturalizado brasileiro, era filho de pai germânico e mãe francesa, radicados no Haiti, atuando naquele país no ramo de importações/exportações. Nascido Ernest Otto Meyer Labastille ${ }^{11}$, ele passou a infância no Haiti, mas em 1904 foi estudar na Alemanha. Apresenta-se, em setembro de 1914, como voluntário para guerra, "ingressando na Infantaria e, em 1917, é transferido para a Força Aérea Prussiana. Recebeu várias condecorações por serviços prestados durante o conflito. Finda a guerra, começa a trabalhar em Hamburgo." (KRIEBEL, 1996, p. 101). Segundo Fay e Oliveira (s.d), Meyer emigrara para o Brasil em 1921, acompanhado de alguns amigos do Exército, devido à precária situação econômica da Alemanha no pósguerra. Na América do Sul, buscavam uma vida melhor. Mais precisamente, como colocado anteriormente, a Alemanha terminara a guerra com excesso de aviões e pilotos formados, mas impedida de manter Força Aérea ou de expandir, oficialmente, linhas aéreas comerciais.

No Brasil, a primeira parada de Meyer seria em Recife ${ }^{12}$. Ali, trabalha para uma empresa de tecidos dos irmãos Lundgren onde convive com as dificuldades da precariedade do sistema rodoviário e ferroviário do País, tornando o transporte naval a opção mais rápida e confortável, entre Recife e Rio de Janeiro (FAY e OLIVEIRA, s. d). De Recife muda-se para o Rio de Janeiro, a serviço de Theodor Willer \& Co, onde também teria fundado uma agência de passagens marítimas. Em 1923, transfere-se para Porto Alegre, por não se adaptar ao clima fluminense e a problemas de malária (KRIEBEL, 1996), indo trabalhar numa empresa de exportação.

\footnotetext{
${ }^{11}$ Em 2 de fevereiro de 1934 torna-se cidadão brasileiro e troca seu nome para Otto Ernest Meyer (KRIEBEL, 1996).

${ }^{12}$ Disponível em: <http://www.preceitos.com/varig/Historia02.html>. Acesso em: 24/10/2008.
} 


\begin{abstract}
De pequena estatura, ágil, 'cabeça dura', cordial, enérgico, dotado de uma grande capacidade de trabalho, Meyer era muito respeitado por seus amigos e querido por todos aqueles que o cercavam nas duras lutas dos idos de 1921. A pacata cidade de Porto Alegre de então nem tomava conhecimento da febril atividade de Otto Ernst Meyer. O mundo rodava devagar, os cafés abrigavam a boemia elegante. A política era coisa só de jornais. A tração animal predominava nos transportes urbanos, havia serestas e os literatos se reuniam em tertúlias. E num documento deixado por Otto Ernst Meyer vamos encontrar aspectos interessantes que retratam suas atividades na época. Disse ele: 'Sempre o chefe deve lembrar-se de que o sólido futuro da obra planejada e o seu próprio sucesso dependerão da escolha e da contínua valorização da equipe, do ambiente de trabalho que ele poderá impor, da honestidade, disciplina e do idealismo dentro da empresa e nas suas relações com as autoridades, imprensa, e freguesia. Neste sentido, esforçamo-nos em transmitir as nossas experiências aeronáuticas provindas da velha Europa ao Brasil, que ambiciosamente, estava tomando consciência da necessidade premente para assegurar, em vista de seus problemas geográficos um lugar importante no então nascente tráfego aéreo comercial. Entretanto, por não estar ainda suficientemente maduro a mentalidade pública e do capital, fracassaram, entre princípios de 1921 e fins de 1924, duas tentativas minhas e de antigos companheiros de armas (Hans Joesting e Hans Cronau) para organizar empresas de transporte aéreo no país'.13
\end{abstract}

Em 1926 é criada a Lufthansa, e a Condor Syndikat encerra suas atividades, "renascendo em dezembro de 1927 como Syndicato Condor, representando os interesses da Lufthansa no Brasil, sendo o principal deles o estabelecimento da ligação aérea entre o Brasil e a Alemanha". ${ }^{14}$

Otto Ernst Meyer passa a articular junto às autoridades locais os planos de fundação de uma empresa aérea, utilizando seus conhecimentos como ex-oficial da Força Aérea alemã, mas também as novas normativas do governo do Brasil. Em 1927, o governo federal sinalizara a liberação do transporte aéreo no país, autorizando precariamente duas empresas estrangeiras para que, durante curto período, realizassem cabotagem. (MALAGUTTI, 2001). Eram elas a Condor Syndikat, alemã, autorizada em 26 de janeiro de 1927, e a Aéropostale, francesa, autorizada em 7 de março de 1927, "visando unicamente o atendimento ao usuário e a integração do território. [...] Trata-se do único caso registrado de autorização para exploração de tráfego de cabotagem, no Brasil, por empresa estrangeira". (idem, p. 3).

Entre 1925 e 1926, Meyer apresentara a proposta de criação da empresa ao "Major Alberto Bins, industrial, fazendeiro, deputado estadual e presidente da

\footnotetext{
${ }^{13}$ Disponível em: <http://www.preceitos.com/varig/Historia02.html>. Acessado em: 24/10/2008.

${ }^{14}$ Idem ibidem.
} 
Associação Comercial, e acima de tudo um homem de visão". (FAY e OLIVEIRA, s. d., p. 3). Segundo a mesma fonte, "Bins, se propõe a dialogar com a autoridade máxima do Estado do Rio Grande do Sul, na época exercida por Borges de Medeiros, com a intenção de convencê-lo a respaldar os planos elaborados por Otto Meyer na criação da companhia de aviação". (idem ibidem). Alberto Bins, então presidente da Associação Comercial e mais tarde prefeito de Porto Alegre, consegue um encontro entre Otto Meyer e o governador Borges de Medeiros, e o orienta a solicitar do mesmo isenção do imposto estadual à futura empresa de aviação aérea, por se tratar de um empreendimento local. Meyer segue a sugestão e, passados 24 dias, em 30 de outubro de 1926, recebe parecer favorável à demanda. ${ }^{15}$ Nascia a Sociedade Anônima Empresa de Viação Aérea Rio Grandense (Varig), já com suporte político e financeiro: "homens de negócios locais, incluindo o Major Bins, formaram o núcleo da companhia proposta e prepararam para vender stock shares para o grande público." (KRIEBEL, 1996, p. 102).

\begin{abstract}
A futura empresa recebeu, em 21 de outubro de 1926, parecer favorável que lhe concedia a isenção de impostos e taxas durante quinze anos. No mês seguinte Otto vai para a Alemanha, tendo consigo a adesão de diversos investidores para o novo negócio. A viagem serviu para a contratação de técnicos, pilotos, mecânicos de bordo e terra e também para estabelecer contatos com os fornecedores de combustíveis e tentar a inclusão em uma das grandes apólices de seguro de uma congênere ou da indústria aviatória. Em Berlim firmou acordo com a Condor Syndikat para o fretamento de serviços durante três meses para operar regularmente sobre a Lagoa dos Patos e a subscrição de 200 mil réis em ações, com o compromisso de adquirir o avião Dornier Wal (Atlântico). (FAY e OLIVEIRA, s. d., p. 3).
\end{abstract}

Kriebel (1996, p. 102) reforça essa informação, dizendo que Meyer teria feito contato, em Hamburgo, com representantes da Deutsch Luft Hansa ${ }^{16}$ e da Condor Syndikat, discutindo um acordo que previa a troca de $21 \%$ das ações da Varig por um futuro leasing do Atlântico, aeronave que no momento passava por adaptações na Alemanha; receberia ainda suporte técnico e o serviço de três homens "o piloto Comandante Rudolf Cramer Von Clausbruch (Luft Hansa ${ }^{17}$ ); o piloto Franz Nuelle (Scadta); e o engenheiro aeronáutico Max Sauer (Condor Syndikat)". ${ }^{18}$ A mesma fonte

\footnotetext{
${ }^{15}$ Disponível em: <http://www.preceitos.com/varig/Historia02.html>. Acesso em: 24/10/2008.

${ }^{16}$ Ver nota 8.

${ }^{17}$ Ver nota 8

${ }^{18}$ Disponível em: <http://www.preceitos.com/varig/Historia02.html〉. Acesso em: 24/10/2008.
} 
acrescenta: "O 'suporte técnico` obviamente incluía a expertise da Condor Syndicat no Brasil, especialmente de seu piloto chefe e especialista técnico, Fritz W. Hammer"19. Meyer teria ainda acertados "a vinda do avião Atlântico ao Brasil, para vôos de demonstração e de estímulo ao empreendimento". ${ }^{20}$

O Atlântico, um aerobote, era impulsionado por dois motores Rolls-Royce de 360 cavalos, velocidade de cruzeiro de $150 \mathrm{~km} / \mathrm{hora}$, tinha oito assentos, cadeiras de vime, a instalação sanitária era um urinol, com tampa, na traseira do hidroplano. Voava com as janelas abertas (fechadas durante a decolagem para evitar entrada de água) e, por isso o barulho era ensurdecedor para os passageiros que usavam algodão nos ouvidos para amenizar o desconforto. ${ }^{21}$

Assinados os acordos, aviões (ou, pelo menos, o Atlântico) são embarcados para Montevidéu por via marítima e de lá voam para Buenos Aires, tendo na tripulação, entre outros, Fritz Hammer. Chegam ao Brasil no mês seguinte, antes do próprio Meyer.

[...] em 17 de novembro de 1926, com Fritz Hammer de novo no controle, o Atlântico transportou o ex-chanceler do Reich alemão, Dr. Hans Luther - um ávido apoiador da aviação civil - em direção ao norte, de Buenos Aires para o Rio Grande do Sul, onde chegou dois dias depois, com recepção triunfal pelos alemães da localidade e pelo Presidente do Brasil. Luther auxiliou na negociação da obtenção de serviços de escalas aéreas. Luther não era um 'estrangeiro' na América do Sul e já havia visitado a Scadta anteriormente, naquele ano. [...]. O famoso 'Vôo Luther' havia demonstrado a reabilitação do Wal e, claro, a capacidade de seus pilotos. [...] Oito dias mais tarde, o Atlântico, agora com o nome em português, mas ainda com registros alemães, fez seu pouso na baia da Guanabara, no Rio de janeiro, em 27 de novembro de 1926. (KRIEBEL, 1996, p. 125).

Os contatos comerciais prosseguiram. No dia $1^{\circ}$ de janeiro, o Atlântico realizou um vôo entre Rio de Janeiro e Florianópolis, via Santos.

Desta vez Hammer não era o piloto, mas um vendedor entusiasmado a bordo, demonstrando os recursos da aeronave, para passageiros ilustres, entre eles Victor Konder $^{22}$, ministro dos Transportes do Brasil; aparentemente impressionado, Konder

\footnotetext{
${ }^{19}$ Idem.

${ }^{20}$ Idem.

21 Disponível em: <http://www.pabloaerobrasil.net/albuns/pages/CONDOR_3.htm>. Acesso em: 02/02/2008

22 "Durante toda a sua vida, Victor Konder foi um entusiasta pela aviação comercial brasileira. Nasceu em Itajaí em 21 de fevereiro de 1886; formou-se em Direito pela Faculdade de Direito do Largo de São Francisco. Em 1922, assumiu a Secretaria de Estado dos Negócios da Fazenda, Viação e Obras Públicas do Governo Hercílio Luz, em Santa Catarina. Em seguida, de 1926 a 1930, ele foi empossado como Ministro de Estado dos Negócios da Viação e Obras Públicas. Durante o período em que exerceu o cargo, o Ministro Victor Konder promoveu incansavelmente a navegação comercial aérea brasileira. Outros
} 
garantiu autorização à Condor Syndikat para operar serviços aéreos por um ano. Este vôo tem sido referido como o de 'começo da aviação comercial no Brasil'. (KRIEBEL, 1996, p. 125).

No avião ainda estavam os jornalistas Raul Portugal e Machado Florence, e o cinegrafista Alberto Botelho. No dia 26 de janeiro, a autorização para que a Condor Syndikat transportasse passageiros e correspondência, é assinada pelo ministro Victor Konder.

Meyer chegara ao Brasil no dia 25 e "às 9h30min da manhã do dia 27 de janeiro de 1927, o Atlântico levantava vôo da baía da Guanabara, aterrissando em Porto Alegre no dia 29, às 12h30min., após ter escalado sob jubilosas recepções em Santos, São Francisco e Florianópolis." 23 Segundo a mesma fonte: "A tripulação era constituída pelo comandante, engenheiro, piloto e o mecânico de bordo. Como passageiros havia o tenente aviador Henrique Fontenelle e Otto Ernst Meyer." ${ }^{24}$ Meyer traz consigo

[...] documentos assinados com a Condor Syndikat, que disponibilizava o comandante Rudolf Cramer Clausbruch (Lufthansa), o mecânico de bordo e segundo piloto, Franz Nuelle (Scadta), o engenheiro Max Sauer (Condor Syndikat), para implantar o serviço regular entre Porto Alegre, Pelotas e Rio Grande. Otto Meyer, em 27 de janeiro de 1927, embarcou no Dornier Wal, batizado de Atlântico, com destino a Porto Alegre, fazendo escalas em Santos, São Francisco e ainda em Florianópolis, com a seguinte tripulação: Von Clausbrusch, Max Sauer, Nuelle e o tenente aviador Henrique Dyott Fontenelle como o representante dos Ministérios da Guerra, Marinha e Viação (FAY e OLIVEIRA, s. d., p. 3).

No dia 3 de fevereiro de 1927, realizou-se o primeiro vôo de estudo, propaganda e escolha do lugar apropriado, nas margens do Saco da Mangueira, em Rio Grande, para a instalação da primeira oficina de conservação, revisão e conserto, montagem e depósito do material em tráfego e a chegar. ${ }^{25} \mathrm{O}$ hidroavião Atlântico, ainda como Condor, inaugura a Linha da Lagoa, ligando Porto Alegre, Pelotas e Rio Grande, em sobrevôo sobre a laguna dos Patos. A bordo, Maria Echenique, representante oficial do

\footnotetext{
tipos de transporte, como o rodoviário, o ferroviário e marítimo, também ocuparam a pauta do Ministro, responsável pelas rodovias Rio-Petrópolis e Rio-São Paulo; pelo projeto completo da eletrificação ferroviária da Central do Brasil; pela construção do porto de Itajaí. Em Blumenau, executou a sua idéia de reunir numa só repartição os Correios e Telégrafos." (Trecho da justificativa ao Projeto de Lei $\mathrm{n}^{\circ}$ 4.590/00, que denomina o Aeroporto de Navegantes como Aeroporto de Navegantes - Ministro Victor Konter, in: http://www.camara.gov.br/sileg/MostrarIntegra.asp?CodTeor=5056), acessado em 20/01/2008.

${ }^{23}$ Disponível em: <http://www.preceitos.com/varig/Historia02.html>. Acesso em: 24/10/2008.

${ }^{24}$ Idem

${ }^{25}$ Idem.
} 
intendente de Porto Alegre e em seu nome levando uma saudação para seus colegas de Pelotas e Rio Grande; Otavio Rocha (Porto Alegre) e João Fernandes Moreira (Rio Grande); Guilherme Gastal e João Oliveira Goulart, como primeiros passageiros. "Também levava malas postais ${ }^{26}$, a título de propaganda. A emoção dominava a todos e o Atlântico foi recebido pela população de Rio Grande, ao acenar de lenços e exclamações de admiração". ${ }^{27}$

Uma versão um pouco diferentes deste vôo é dada por Oswald Heinrich Müller $^{28}$, admitido como funcionário da Condor Syndikat no dia 15 de junho de 1927 , pois a companhia aérea alemã precisava de funcionários que falassem a língua estrangeira, já que seus técnicos alemães não falavam o português. Muller fora indicado para o cargo por Ruben Berta, de quem fora colega no curso secundário, no Ginásio Farroupilha, de Porto Alegre. Muller disse ter participado deste primeiro vôo no Atlântico,

[...] o primeiro e, na época, o único hidroavião da companhia. Diferente do que noticiaram os jornais, o vôo inaugural da Varig em 22 de junho de 1927 não levou passageiros com passagens pagas porque a licença ainda não havia sido publicada. Além da tripulação, apenas um, Oswald H. Müller, funcionário da Condor. Uma semana após ter sido admitido na empresa, Oswald foi enviado para o Rio de Janeiro como secretário do diretor-técnico Max Sauer. (SOCIEDADE GERMÂNIA, 2005, s. p.).

\footnotetext{
${ }^{26}$ Além dos passageiros o aerobote transportou 162 de correspondência postal. Disponível em: <http://www.pabloaerobrasil.net/albuns/pages/CONDOR_3.htm.>. Acesso em: 02/02/2008.

${ }^{27}$ Disponível em: <http://www.preceitos.com/varig/Historia02.html>. Acesso em: 24/10/2008.

28 "Oswald Heinrich Muller foi o primeiro aeroviário da Sindicato Condor Ltda. Aposentou-se, por idade, em 1975 quando era diretor de operações. Fez minuciosas pesquisas e publicações da memória da aviação, com destaque para o pioneirismo da Condor na implantação da aviação comercial brasileira. Recebeu correspondência do Ministro da Aeronáutica, Brigadeiro Marcio de Souza Melo, em 1971, afirmando que "não encontrava expressões adequadas à bem traduzirem o quanto me impressionou o vulto e a meticulosidade que abalisam seu acurado trabalho 'O início da aviação comercial brasileira' [...]. Aceite, portanto, com cordial abraço o agradecimento e o aplauso do antigo companheiro de lutas pela sobrevivência da Cruzeiro'. Esse documento que foi solicitado pelo Ministro foi posteriormente encaminhado a Lufthansa, patrocinadora da Condor. Na época, Assis Chateaubriand escrevia no Diário de São Paulo: 'Ela é a grande pioneira. É a magnífica desbravadora. Fez as linhas menos desejáveis. Ajudou a criar um espírito aeronáutico em nossa terra, e por esse esforço de bandeirismo não lhe seremos, jamais, bastante agradecidos'. Muller serviu 48 anos a Condor. O Jornal do Brasil o entrevistou quando se devia comemorar o cinquentenário Serviço Postal Aéreo (a primeira mala postal foi transportada pela aeronave da Condor. Attântico, prefixo D-1012, no dia 18 de junho de 1927, sob o comando do piloto Cramer von Clausbruch), em 1977, sem nenhuma programação oficial: 'No baú de relíquias - publicou o jornal - o aeroviário foi buscar catálogos, , selos valiosos, reportagens e cartas de Ministros para mostrar a importância do serviço aéreo comercial e da mala postal no país'. Ele, Sr. Muller, diz o jornal, ingressou na Condor com 22 anos e por 18 anos foi diretor da empresa, residindo no Rio de Janeiro. Como conselheiro aposentou-se em 1975. Essa data deveria ser considerada oficialmente pelo governo brasileiro como um marco histórico na implantação da aviação comercial no Brasil". Disponível em: <http://www.pabloaerobrasil.net/albuns/pages/CONDOR_14.htm.>. Acesso em: 02/02/2008.
} 
Ainda sobre os vôos iniciais da aviação civil, Muller explicou:

[...] eram considerados muito corajosos aqueles que se aventurassem a participar de uma viagem pelos ares. Os primeiros aviões comerciais eram lerdos, sua velocidade era no máximo $150 \mathrm{~km} / \mathrm{h}$. As janelas eram abertas durante o vôo, mas fechadas antes do pouso, para evitar a entrada de água quando a superfície estava agitada. $\mathrm{O}$ barulho dos motores era ensurdecedor e os passageiros tinham que usar algodão nos ouvidos. O entendimento durante o vôo só era possível aos berros. Os aeronautas munidos de óculos de aviador e trajando roupa de couro viajavam ao tempo, expostos às intempéries, apenas abrigados por um pequeno pára-brisa. Como instalação higiênica encontrava-se a bordo um penico ${ }^{29}$. (SOCIEDADE GERMÂNIA, 2005, s. p.).

Este vôo, polêmica a parte, é comemorado como o começo da aviação comercial no Brasil, "embora ele não seja o início das escalas regulares - o Atlântico foi alocado para atender Rio Grande - o que tem que esperar até 22 de fevereiro. A publicidade, entretanto foi um sucesso, e novos acionistas potenciais surgiram em todo Rio Grande do Sul”. (KRIEBEL, 1996, p. 102).

Era a arrancada final para o funcionamento da nova empresa. A esta altura, necessitando muito do auxílio de um secretário para vencer o fabuloso aumento dos mais deferentes serviços, Otto Ernst Meyer publicou o respectivo anúncio. Foram poucos os que se apresentaram. O salário não era dos melhores e, além disso, faltava confiança no êxito do negócio. Um candidato, porém, vigoroso, moço de 19 anos conta Otto Meyer - que nenhuma importância quis dar ao que lhe poderia oferecer de ordenado do meu bolso, muito me interessou e logo o convidei a pendurar o chapéu e o casaco no cabide e pôr em movimento a máquina de escrever, para que, juntos, tentássemos vencer aquela avalanche de trabalho, pronta para soterrar a iniciativa. Até hoje, a Varig nunca se arrependeu dessa escolha. Chamava-se Ruben Martin Berta, o 'moço vigoroso` que se tornou o primeiro funcionário da navegação aérea no Brasil, e mais tarde sucessor de Otto Ernst Meyer, na presidência da empresa. Os dois - Meyer e Berta - faziam tudo: limpavam o escritório, tratavam da propaganda, da administração, e etc. Trabalho intenso, árduo, paciente. ${ }^{30}$

Outro documento assinado pelo ministro Konder, no dia 17 de março, não pode ser desconhecido. A Instrução foi publicada no Diário Oficial de 19 de maio de 1927 e tinha como objeto a execução de transporte de correspondência por via área. Trata-se de um documento "que mudaria a história aérea - e filatélica - do país" (KRIEBEL, 1996, p. 126), autorizando aos agentes de transporte, a emissão de selos especiais, para com eles coletarem fundos que ressarcissem seus serviços. Isso fora uma sugestão do

29 Essa instalação sanitária, um urinol com tampa, estrategicamente colocado na parte traseira do hidroplano, também é referenciada no endereço disponível em: <http://www.buscaerea.com.br/farejador/farejador02.html>. Acessado em: 02/02/08.

${ }^{30}$ Disponível em: <http://www.preceitos.com/varig/Historia02.html>. Acessado em: 24/10/2008. 
Comandante Hammer ao ministro, dando como exemplo o sucesso de medida semelhante, na Colômbia.

Por um período de seis meses, a partir do início da operação pela empresa, seria permitido o uso de carimbos ou de qualquer outro dispositivo conveniente para as transportadoras, em lugar dos selos. Pela Instrução, o serviço poderia ser realizado apenas por empresas domésticas, especialmente autorizadas. O design dos selos também deveria receber autorização prévia, mas a correspondência deveria receber, também, os selos normais de postagem, emitidos pelo órgão oficial do governo. Uma tabela de valores foi estabelecida, de acordo com a distância percorrida. ${ }^{31}$ Nos dias 27 e 28, a Condor Syndikat realiza o primeiro vôo levando correspondência, a bordo do Atlântico e, após dois meses já teria realizado 50 vôos com este objetivo.

Os vôos promocionais conduzindo autoridades ou carregando malotes de Correio, deram grande visibilidade aos serviços aéreos. "O entusiasmo envolvera todo o Rio Grande do Sul, e assim, surgiram novos subscritores de ações em todo o Estado. Em $1^{\circ}$ de abril de 1927 foi convocada a primeira assembléia preparatória" ${ }^{32}$, em que foi apresentado e discutido o projeto de estatuto da empresa, elaborado por Adroaldo Mesquita da Costa $^{33}$ e Carlos Maria Bins. A Assembléia foi realizada na Associação Comercial de Porto Alegre. Serão dez os sócios fundadores: José Bertaso, Charles Freb, Arthur Bromberg, Rodolfo Ahrens, Adroaldo Mesquita da Costa, E. Gertum, Waldemar Bromberg, Jorge Pfeifer e Ernesto Rotmund. ${ }^{34}$

\footnotetext{
${ }^{31}$ A Condor foi a primeira a usar os selos, o que fez até 30 de novembro de 1930, quando passou a atender os serviços internacionais de Correios, em parceria com a Zeppelin com os navios da Domier. "O uso de selos pela Varig foi descontinuo até 1 de julho de 1934 [...]. ETA, a outra companhia a emitir selos sob as prescrições da Secção 5, suspendeu a operação em 1930.” (KRIEBEL, 1996, p. 162).

${ }_{32}$ Disponível em: <http://www.preceitos.com/varig/Historia02.html>. Acesso em: 24/10/2008.

${ }^{33}$ Adroaldo Mesquita da Costa (Taquari, 1894 - Taquari, 1985), bacharel em Direito e em Ciências e Letras, colou grau em 1911; deputado na Assembléia Constituinte Federal, de 14.12.1933 a 18.07.1934; deputado estadual pela Frente Única Riograndense, de 12.04.1935 a julho de 1935; deputado estadual pelo Partido Republicano Riograndense, de 08.07.1935 a 10.11.1937; deputado constituinte federal de 05.02.1946 a 18.09.1946 pelo Partido Social Democrático; deputado federal, também pelo PSD de 23.09.1946 a 10.04.1950. Durante o período de 14.11.1947 a 10.04.1950, afastou-se da Câmara, por ter sido nomeado Ministro da Justiça e Negócios Interiores, no governo Gaspar Dutra, em substituição a Benedito Costa Neto. Foi ainda professor da Faculdade de Direito de Porto Alegre, nomeado em 14.06.1938 e professor da Faculdade Livre de Filosofia, Ciências e Letras e Direito Comercial da Faculdade de Direito da PUCRS; ministro da Justiça, de 04.11.1947 a 01.04.1950; vereador em Taquari, de 08.02.1956 a 31.12.1959; secretário estadual da Educação e Cultura do RS de 03.07.1958 até 31.01.1959; de 1964 e 1969, foi Consultor-Geral da República. Disponível em: <http://www.mp.rs.gov.br/memorial>. Acesso em: 15/02/2008.

${ }^{34}$ Disponível em: <http://www.preceitos.com/varig/Historia02.html>. Acesso em: 24/10/2008.
} 
Na mesma semana, foi publicado um anúncio convidando os novos acionistas para fazerem parte do empreendimento. $\mathrm{O}$ apelo vingou e assim, a primeira Assembléia Geral, em 7 de maio de 1927, secretariada por José Bertaso e Theofilo de Barros, reuniu 550 acionistas de Porto Alegre, Pelotas, São Leopoldo, Rio Grande, Novo Hamburgo e Cachoeira, que estabeleceram a fundação da Varig e a eleição dos seus diretores: Otto Ernst Meyer, como Diretor Administrativo; Rudolf Cramer von Clausbruch, como Diretor Técnico; Fritz Hammer e o Major Alberto Bins, como diretores membros do Conselho Fiscal e Carlos Albrecht Jr., Max Sauer e o Barão von Duddenbrok, como demais integrantes do Conselho ${ }^{35}$. A sociedade teria aclamado,

[...] comovida, a fundação da primeira empresa aérea brasileira, a Varig com sede em Porto Alegre, Rio Grande do Sul, Brasil. Grande parte do grupo de homens idealistas que se reuniu na pequena sala da Associação Comercial de Porto Alegre naquele dia, mal poderia sonhar que o papel que estava ali para ser assinado iria produzir um gigantesco complexo, uma companhia que se tornaria conhecida e respeitada em todo o mundo. E mais ainda: com seu conceito firmado em cada canto do seu país natal, representando papel preponderante na vida nacional. Aqueles tenazes pioneiros não poderiam imaginar aonde chegaria a sua pequena companhia, mas certamente sabiam que seus objetivos imediatos eram bastante realistas. Acima de tudo, tinham fé no Brasil e nos brasileiros, grande coragem e desprendimento, sentimentos e qualidades que também são encontrados em todos os que trabalham para a Varig hoje. ${ }^{36}$

A Varig foi oficialmente registrada em 7 de maio de 1927 e "obteve autorização governamental para operar em 10 de junho de 1927”. (MALAGUTTI, 2001, p. 4), com vôos no Rio Grande do Sul, costa de Santa Catarina, e com permissão uruguaia, para Montevidéu. A Condor começará a operar vôos regulares entre Rio de Janeiro e Porto Alegre, em 9 de novembro do mesmo ano. Sobre os vôos iniciais, há outras curiosidades:

Em carta ao autor, o aeroviário e, posteriormente diretor da Condor, Oswald Heinrich Muller declarou que, em algumas condições de ausência de vento, ele utilizava a lancha da Condor para fazer "marola" e, assim facilitar a decolagem "no tranco" do Atlântico. O vôo era baixo, continuava Sr. Muller, propiciando descortinar o belo panorama. 'Ruim mesmo era para os pilotos que ficavam logo abaixo dos motores, expostos ao tempo'. A aeronave era segura e só fazia vôos com bom tempo. Cada passageiro que tivesse mais de $75 \mathrm{~kg}$ pagava excesso ( $1 \%$ da passagem por cada quilo acima $)^{37}$.

\footnotetext{
${ }^{35}$ Idem

${ }^{36}$ Idem

37 Disponível em: <http://www.pabloaerobrasil.net/albuns/pages/CONDOR_3.htm>. Acesso em: 02/02/2008.
} 


\section{VARIG: PERÍODO OTO ERNEST MEYER}

Meyer, o ativo participante na criação da Varig, comandará a empresa até 1941, quando se afasta da direção, em função da perseguição política aos (possíveis) simpatizantes do nazismo, o que atingiu diretamente os núcleos alemães do Rio Grande do Sul (FAY E OLIVEIRA, s.d.). Esta segunda fase de sua administração envolve o afastamento da Condor e as agruras dos primeiros passos solo, não raro com apenas um avião. Neste período, mais do que no anterior, os contratos para transporte de malotes postais foi fundamental, assim como a íntima ligação com as forças políticas do momento.

Em 15 de junho de 1927, findo o contrato de fretamento dos serviços da Condor Syndikat, de Berlim, o mesmo recebeu "consideráveis compensações, Hammer passando a ter acento no board de diretores" (KRIEBEL, 1996, p. 103). O comandante Cramer von Clausburch, o mecânico de bordo e o piloto passaram a integrar o quadro de funcionários da Varig. Também o hidroavião Dornier Wal Atlântico foi transferido para a Varig em troca de 1.000 ações (US\$ 50.000), e registrado como P-BAAA ${ }^{38}$; seria a primeira aeronave sob as novas regras brasileiras. A Varig assume, com plena responsabilidade, os serviços na sua linha tronco sobre a Lagoa dos Patos, entre Porto Alegre, Pelotas e Rio Grande e, no dia 22, sete dias após, faz seu primeiro vôo, substituindo a Condor no Rio Grande do Sul. (KRIEBEL, 1996, p. 128).

A Condor será nacionalizada como Sindicato Condor, com registro em $1^{\circ}$ de dezembro de 1927, passando a

[...] operar em 15 de julho de 1928, com equipamentos da empresa alemã, nacionalizada. Ao final da década dos 1930, a empresa teve seu nome alterado para Serviços Aéreos Condor, passando a Serviços Aéreos Cruzeiro do Sul em 1943, durante a Segunda Guerra Mundial, em decorrência de restrições governamentais ao seu nome resultante da empresa alemã. (MALAGUTTI, 2001, p. 4).

No seu período de implantação, são muitos os liames que ligam as empresas aéreas, às forças políticas constituídas ou em constituição. Fay (s.d.) registra:

Em 29/03/1929, Getúlio Vargas realizou seu primeiro vôo no primeiro avião a voar comercialmente no Brasil, o Atlântico, nesse momento pertencente ao Sindicato Condor. No final do mesmo ano, quando foi ao Rio de Janeiro para

\footnotetext{
${ }^{38}$ Disponível em: <http://www.preceitos.com/varig/Historia02.html>. Acesso em: 24/10/2008.
} 
ler sua plataforma de candidato a Presidente, também usou o avião como meio de transporte. Ao chegar ao Rio, no final da tarde, e sobrevoar o centro, o Atlântico provocou um tumulto na cidade: uma multidão deslumbrada correu para a Praça Mauá para assistir ao desembarque de Vargas.

Em vários discursos durante esse período, Vargas teria deixado clara a importância do transporte aéreo no Brasil.

A década de 1930 marca-se pelas dificuldades da empresa em sobreviver, longe do abrigo da Condor. A demanda de tráfego era ainda modesta e a situação política do país passava por alguns momentos turbulentos. Suas aeronaves apresentariam lucros módicos, em operações restritas ao Rio Grande do Sul que atendiam cidades como Porto Alegre, Pelotas, Cruz Alta, Santana do Livramento, Bagé, Santa Maria e linhas sazonais, como aquelas em direção às localidades litorâneas como Torres e Tramandaí na temporada de verão, ou quando da realização de eventos especiais como a Festa da Uva, em Caxias do Sul (KRIEBEL, 1996). Somavam-se a isso a obrigação de implantar instalações, mesmo que mínimas, imprescindíveis para a operação das aeronaves. (UBIRATAN, s. d.).

Em termos políticos, em 1930 houve a crise que levou à posse de Getúlio Vargas, episódio em que haveria "alguns indícios de que a empresa aérea nativa do Rio Grande Sul teria dado suporte a operações paramilitares conectadas e em apoio à revolução.” (KRIEBEL, 1996, p. 108). Em 1932 seria a vez da revolução paulista, entre julho e setembro. São Paulo é bombardeada pelo ar, "possivelmente por aeronaves da Varig [...]." (idem, p. 111).

No início da década de 1930, precisando expandir suas operações, a Varig recorre ao Estado, que disponibilizou à empresa, em forma de aluguel, um campo de pouso na cidade de Gravataí, e liberou recursos para a construção de um hangar. (FAY E OLIVEIRA, s. d., p. 4). O Atlântico continua quase solitário na frota, de maneira que a Varig solicita subsídios também para leasing de novos aviões. Em abril de 1930, ela recebe dois Junkers F-13, prefixos P-BAAF e P-BAAG, iniciando a rota para Livramento, Santa Cruz e Cruz Alta. Em maio, 1.050 ações da Varig pertencentes à Condor Sindikat foram transferidas ao governo do Rio Grande do Sul (FAY e OLIVEIRA, s. d., p. 4), cumprindo um contrato de subvenção, celebrado em maio daquele ano, no valor de 1.200:000\$000 (mil e duzentos contos de réis). (UBIRATAN, s. d.). 
Ainda em 1930, vieram o Junker G24, Ypiranga, seguido pelo Wal Domier, Gaúcho, ambos hidroaviões. O Gaúcho, utilizado "pela Lutf Hansa na rota BerlimMoscou, foi modificado como float plane. Ligeiramente maior que o Junker F13, seu motor único poderia ter mais força e suportar seis passageiros em vez de quatro". (KRIEBEL, 1996, p. 194). Os novos aviões permitem que, no dia 6 de setembro do mesmo ano, seja inaugurada a rota Porto Alegre-Passo Fundo, com o avião Gaúcho pilotado por Franz Nuelle ${ }^{39}$. Mas, como agora serão necessários pousos em terra, a Varig devolve à Condor os dois aviões e adquire dois Klemm da ETA, empresa brasileira que havia quebrado após curto tempo de vida. Mas, logo, um deles se acidenta e a Varig volta a ter apenas um avião. Nos anos seguintes, outros aviões são adquiridos e as rotas ampliadas. A Varig chega a 1936 com transporte de passageiros, Correios e cargas o que lhe permite estabelecer a primeira linha aérea diária no Brasil, entre Porto Alegre e Pelotas. "Os resultados financeiros de 1935 e 1936 foram suficientemente positivos para permitir a compra de novos aviões". (UBIRATAN, s. d.).

\begin{abstract}
Vendo-se na obrigação de suspender a linha Porto Alegre-Rio Grande em 1938, devido às baixas taxas de ocupação, Otto-Ernst Meyer, junto ao Departamento de Aeronáutica Civil buscou uma solução a fim de não deixar Rio Grande completamente sem comunicação aérea com Porto Alegre. Após alguns estudos a VARIG fechou um acordo com a Viação Férrea do Rio Grande do Sul com o intuito de conjugar horários, assim estabeleceu como resultado o primeiro tráfego mútuo avião-trem do Brasil e um dos primeiros do mundo. Adquirindo a passagem, o passageiro completava o trecho Porto Alegre-Pelotas de avião e após desembarcar em Pelotas um automóvel o levava até a estação onde o passageiro embarcava em um trem que o levaria até a cidade de Rio Grande. Esse sistema foi um grande sucesso incentivando a VARIG a implantar um sistema semelhante levando o passageiro até Montevidéu ou Buenos Aires. No entanto um período difícil começava a apontar ao horizonte com o início da Segunda Guerra Mundial. Contando unicamente com aviões de origem alemã a Varig começou a sentir as dificuldades em importar material aeronáutico alemão. (UBIRATAN, s. d.).
\end{abstract}

A Varig, durante 15 anos teve como presidente seu fundador, Otto Ernst Meyer, e como o braço direito deste, Ruben Martin Berta, o primeiro funcionário da companhia que mais tarde torna-se o sucessor de Otto Meyer (FAY e OLIVEIRA, s. d., p. 4). "Em 1941, quando o Brasil tomou posição na guerra, ao lado dos aliados, contra a Alemanha,

\footnotetext{
39 Esta e demais informações deste parágrafo construídas a partir de Fay e Oliveira (s. d.); Fay (s. d.); Ubiratan (s. d.); Kriebel (1996); e em http://www.preceitos.com/varig/Historia02.html
} 
Otto Ernst Meyer, considerando sua origem e para evitar possíveis dificuldades à empresa, achou por bem renunciar à presidência, embora fosse instado a não fazê-lo" 40 .

O Governo do estado do Rio Grande do Sul como acionista majoritário indicou ao cargo Érico de Assis Brasil ${ }^{41}$. No entanto, sua morte duas semanas depois da nomeação o impediu que fizesse algo pela VARIG. Imediatamente uma nova reunião foi convocada pelos acionistas e Ruben Martin Berta, o braço direito de Otto-Ernst Meyer foi nomeado o novo Diretor-Gerente da Varig. Que obteve a árdua tarefa de conduzir a VARIG através dos difíceis obstáculos que já se apresentavam, tarefa que ele desempenhou com enorme habilidade. (UBIRATAN, s. d.).

Com Rubem Berta, a Varig ganhará novos ares, que a levarão a ser, por largo período nas décadas seguintes, a principal empresa aérea do Brasil

\section{EPÍLOGO}

O período de implantação aqui analisado, propôs apresentar como o campo da aviação civil se constituiu no Brasil, destacando a experiência da Varig. A implantação do transporte aéreo, como colocado, se deu em consonância com processos semelhantes, que atingiram o transporte aéreo em outros pontos da América do Sul. Ou seja, houve a necessidade de apoio público e governamental para aquisição não só de aviões e de outros equipamentos, como para implantação de infraestrutura, como pista de pouso e hangares para carga e passageiros, mesmo que mínimas. (Figura1).

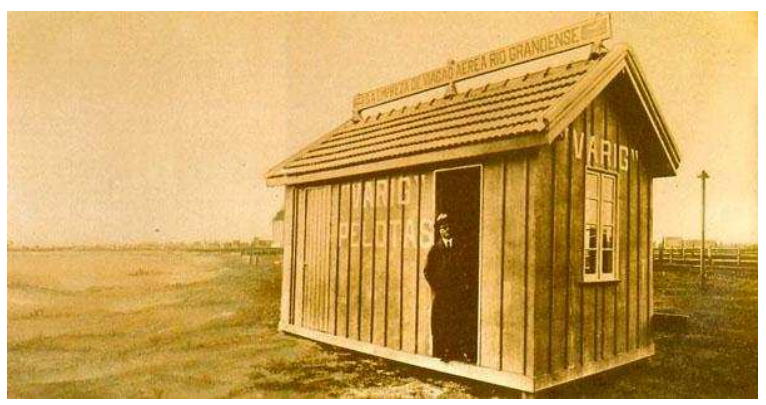

FIGURA 1: PELOTAS, 1929. PRIMEIRA ESTAÇÃO DE PASSAGEIROS DA VARIG FONTE: HTTP://WWW.PRECEITOS.COM/VARIG/AEROPORTOS.HTML

\footnotetext{
${ }^{40}$ Disponível em: <http://www.preceitos.com/varig/Historia02.html>. Acesso em: 24/10/2008.

${ }^{41}$ ERICO DE ASSIS BRASIL: Bacharel em Direito, ex-chefe de Gabinete do então Coronel Oswaldo Cordeiro de Farias, interventor federal no Rio Grande do Sul. Faleceu, nessa função, em 1942, em acidente aéreo ao pilotar uma aeronave. Disponível em: <http://assisbrasil.org/segunda.html〉. Acesso: em 30/01/08.
} 
A Varig recebeu subsídios do poder público e apoio financeiro de empresários locais, para sua criação e implantação. Mas, tanto para Varig como para outras empresas aéreas do continente, outro subsídio importante seriam as concessões para Correio Aéreo. Segundo Kriebel (1996), a contraparte pelos serviços de Correio se dava via autorização para impressão de selos. No caso da Varig, haveria um adicional importante nesses termos, pois Oto Meyer seria filatelista e, parece, teria clareza em relação a esse importante mercado colecionador (GASTAL, 2009). Pela norma governamental de 1927, quem recebesse a concessão de Correios poderia cobrar além da taxa postal usual, a ser encaminhada ao governo, uma taxa extra pelo transporte aéreo. A mesma norma autorizava as empresas a imprimir selos como forma de coletar fundos para ressarcimento de seus serviços; provisoriamente, poderiam utilizar carimbos ou outros, para identificar pacotes e envelopes, considerados pré-estampas. (MALAGUTTI, 2001)

Enquanto parceira da Condor, também os selos das duas empresas eram conjuntos. Já em 1927 foram utilizados na Linha da Lagoa dos Patos, carimbos na forma de triângulo provisórios (KRIEBEL, 1996). Os envelopes traziam a frase: "O futuro do Brasil depende de suas comunicações”. Em 15 de junho de 1927, quando a Varig assumiu sozinha a Linha da Lagoa, o nome da empresa no carimbo é trocado, mas a frase é mantida (idem).

Os primeiros selos da Varig foram impressos na Alemanha, pela Reichsdruckerei, de Berlim (idem). Em 1931, os selos passam a ser impressos na Editora Globo, em Porto Alegre (UFPA, 1935). A Editora Globo era de propriedade da família Bertaso, que esteve entre os primeiros subscritores das ações da Varig. Ou seja, na associação entre a aviação comercial e o Correio Aéreo, há a participação de diferentes segmentos sociais - no caso, gráficos, designers e todo poderoso campo filatélico - para além do que aproximações apriorísticas poderiam sugerir, e indica que o campo do Turismo, na sua construção, envolve uma diversidade de atores e não apenas aqueles que, na atualidade, estariam arrolados como trade turístico.

Significativa, também, foi a ampla presença da função Correios, associada ao desenvolvimento das viagens, mesmo em períodos anteriores ao surgimento do avião, como mostram os relatos sobre as viagens de Goethe. Foram as agências postais que primeiro se encarregaram do transporte, da alimentação e do pernoite dos viajantes. Depois, a função Correios encaminhou a viabilidade econômica das empresas aéreas 
pioneiras, como a Varig, na ausência de outros capitais locais, que pudessem subsidiálas. Ou seja, a construção do campo do turismo é bastante complexa, e seu estudo ainda está por ser melhor aprofundado.

\section{REFERÊNCIAS}

BARTHES, R. O rumor da língua. São Paulo: Brasiliense, 1988.

BOURDIEU, P. Pierre Bourdieu: sociologia. São Paulo: Ática, 1983.

BOYER, M. História do turismo de massa. Bauru: EDUSC, 2003.

FAY, C. M. Getúlio Vargas e o desenvolvimento da aviação brasileira. ViaPolítica. Disponível em: <http://www.viapolitica.com.br/outro_olhar_getulio.ph>. Acesso em: 02/02/2009.

FAY, C. M. e OLIVEIRA, G. G. A Varig e suas vozes silenciadas. Disponível em: $<$ http://www.cfh.ufsc.br/abho4sul/pdf/Claudia\%20Fay;\%20Geneci\%20de\%20Oliveira. pdf>. Acesso em: 02/02/2009

GASTAL, S. Ações comunicacionais e transporte aéreo no Brasil: Os passos iniciais da Varig. Anais do XXXII Congresso Brasileiro de Ciências da Comunicação. Curitiba, setembro de 2009.

JAMESON, F. Espaço e imagem: teorias do pós-moderno e outros ensaios. Rio de Janeiro: Editora UFRJ, 1992.

KRIEBEL, W. V. Correio Aéreo. A history of the development of Air Mail Service in Brazil. Mineola/NY: The American Air Mail Society. 1996.

LAVENERE-WANDERLEY, N. F. História da Força Aérea Brasileira. São Paulo: CR Correa Publicações Aeronáuticas, 1975.

MalagutTi, A. O. Evolução da Aviação Civil no Brasil. Brasília: Câmara dos Deputados, 2001.

SCHMIDT, H. A arte de viajar. Humboldt, n. 54. Bonn: Inter Nationes, 1987

SOCIEDADE GERMANIA. Oswald Heinrich Müller 100 anos de história. Boletim Informativo da Sociedade Germânia. Ano 5, n. 30, Porto Alegre/RS, Novembro/Dezembro 2005. Disponível em: $<$ http://www.sociedadegermania.com.br/boletins/boletim30.pdf $>$. Acesso em: 20/09/2008. 
SOUZA, J. G. A epopéia do Correio Aéreo. Rio de Janeiro: Revista Aeronáutica Editora, 1986.

UBIRATAN, Edmundo. VARIG - 79 Anos de História. Disponível em: <http://www.aironline.com.br/paginashistoria/1505.htm>. Acesso em: 20/09/2008.

UFPA - União Filatelista Porto Alegrense. Catálogo Histórico e Descriptivo dos Sellos da Varig. Porto Alegre: UFBA, 1935.

\section{Sites consultados}

http://assisbrasil.org/segunda.html. Acesso em: 30/01/2008

http://edairways.sites.uol.com.br/varig.htm. Acesso em: janeiro de 2009.

http://www.buscaerea.com.br/farejador/farejador02.html. Acesso em: 02/02/2008.

http://www.camara.gov.br/sileg/MostrarIntegra.asp?CodTeor=5056. Acesso em: 20/01/2008.

http://www.mp.rs.gov.br/memorial. Acesso em: 15/02/2008

http://www.pabloaerobrasil.net/albuns/pages/CONDOR_3.htm. Acesso em: 02/02/2008.

http://www.pabloaerobrasil.net/albuns/pages/CONDOR_14.htm. Acesso em: 02/02/2008.

http://www.preceitos.com/varig/Historia02.html. Acesso em: 24/10/2008

Recebido em: 22/04/2009

Aprovado em: 22/05/2009 